\title{
The Relationship Between Autism Symptomatology, Performance, Experienced Problems, and Benefits in Problem-Based Learning Curricula
}

\author{
Kristel de $\operatorname{Groot}^{1,2}$ (D) Guus Smeets ${ }^{1}$
}

Published online: 30 September 2017

(C) Springer International Publishing AG 2017

\begin{abstract}
The attention for supporting students with autism spectrum disorder (ASD) at university has recently grown. However, no research to date has looked into the fit between autism symptomatology and a specific form of education, problem-based learning (PBL). To examine the fit between individuals scoring high on the autism spectrum and the characteristics of PBL, a new questionnaire was developed that focuses on the core elements of PBL: learning as a constructive, self-directed, collaborative, and contextual process. This new questionnaire and an ASD symptomatology questionnaire, the Autism-Spectrum Quotient (AQ), were filled out online by university social sciences and humanities students. The findings show that higher ASD symptomatology predicted experiencing more problems $(F(3,103)=15.24, p<.001$, $\left.R^{2}=.31\right)$ and fewer benefits $(F(3,103)=10.28, p<.001$, $\left.R^{2}=.23\right)$ of PBL. However, these experiences were not accompanied by lower grades $(F(3,103)=0.36, p=.784$, $\left.R^{2}=.01\right)$. These results are in contrast with previous findings from traditional, lecture-based curricula, in which students scoring high on the autism spectrum perform worse than students scoring low on the autism spectrum. The discrepancy between experiencing more problems and less benefits but no effect on performance is explained by accommodation and
\end{abstract}

Kristel de Groot

k.degroot@ese.eur.nl

1 Erasmus School of Social and Behavioural Sciences (ESSB), Erasmus University Rotterdam, Rotterdam, the Netherlands

2 Erasmus University Rotterdam Institute for Behaviour and Biology (EURIBEB), Erasmus University Rotterdam, Rotterdam, the Netherlands desirable difficulties, stating that the characteristics offered by PBL might help students scoring high on the spectrum develop the skills necessary to succeed in (university) education.

Keywords Autism spectrum disorder (ASD) - University education · Students $\cdot$ Problem-based learning $(\mathrm{PBL}) \cdot$ Autism spectrum hypothesis

\section{Introduction}

Autism was first described by Kanner (1943) in 11 cases of children that had limited communicative capacities, good but atypical cognitive abilities, and behavioural problems such as obsessiveness, repetitive actions, extreme aversion of change, and lack of imaginative play. Based on these case studies, Kanner described the symptomatology as 'inborn autistic disturbances of affective contact' (Kanner 1943 p. 250). Around the same time, the Austrian paediatrician Asperger (1944) described in essence the same disorder as 'autistic psychopathy', but partly because the publication was written in German, it only gained attention after being translated by Frith (see Asperger 1991). Now, more than 70 years later, autism and its symptoms have become well-known. The newly released fifth edition of the Diagnostic and Statistical Manual of Mental Disorders (DSM-5, American Psychiatric Association 2013) covers all pervasive developmental disorders (autistic disorder, Rett's Disorder, childhood disintegrative disorder, Asperger's Disorder, and pervasive developmental disorder not otherwise specified) under the broad term autism spectrum disorder (ASD), which is seen more in males than in females, and has a prevalence around 1 in 132 individuals (Baxter et al. 2015; Wicks-Nelson and Israel 2012). Diagnosis is based on behavioural and cognitive 
characteristics (Mulder and Cashin 2014; Spek 2010) that are seen in differing degrees of severity in individuals across the autism spectrum. On the behavioural level, social-emotional deficits, (non-)verbal communication deficits, and stereotypical, restricted, and repetitive behavioural patterns are seen as characteristic of ASD (Mulder and Cashin 2014; Spek 2010; Wicks-Nelson and Israel 2012). On the cognitive level, individuals with ASD process information differently than typically developing (TD) individuals (Mulder and Cashin 2014; Spek 2010; Spek et al. 2010, 2011; Wicks-Nelson and Israel 2012). This is seen in rigid executive functioning (having less flexible thought patterns), weak central coherence (local instead of global information processing, seeing details instead of the integrated whole), impaired theory of mind (TOM; being less able to put yourself in someone else's shoes, also known as mind blindness), and hyper- or hypo-reactivity to sensory stimuli such as sounds and smells. It is important to note that although many individuals with ASD show all these characteristics to a certain degree, the characteristics do not form a definite diagnostic criterion. Not all individuals diagnosed with ASD show all mentioned characteristics, and most characteristics are not specific to ASD.

The pervasive nature of ASD means it impacts all areas of life, including education. Despite the possible impact of ASD on educational experience and performance, the recent increase of students with ASD in higher education was initially not accompanied by an equally strong increase in research on the possible problems these students experience in educational settings (Gelbar et al. 2014; Gobbo and Shmulsky 2014; Knott and Taylor 2014; Mulder and Cashin 2014; Pinder-Amaker 2014). Only the last few years, research has started to look into the problems students with ASD face, although there is still little focus on supporting these students at university. Often, universities do not realise that students on the autism spectrum may encounter specific problems in studying and functioning at university, and that they might need special support to successfully complete their education. This is especially relevant since students with ASD do often not lack intellectual capacities or motivation. In addition, they certainly possess some academic strengths that would be wasted if not used, such as being passionate about the course material and studying, having a desire to know, and greater than average adherence to rules, procedures, and appointments (Gobbo and Shmulsky 2014).

Research suggests that students with ASD often experience problems and challenges that are specifically related to ASD symptomatology, and that impair their academic functioning. One such problem concerns hyper-reactivity (Knott and Taylor 2014). Getting over-aroused by sensory stimuli can happen in classes, leading to an inability to concentrate. It can also happen in halls and dorms, where students have to deal with noisy neighbours, and smelling a lot of different fragrances in a shared kitchen. Another problem reported by students with ASD is related to their cognitive setup: ASD is usually accompanied by a preference for bottom-up processing, causing students with ASD to experience difficulty with instructions and assignments that highly depend on top-down processing (Gobbo and Shmulsky 2014). In addition, students with ASD often report having difficulties with prioritising, organising, time management, initiating and aborting working on assignments, quick shifting between different sources of information or different subjects, and planning, especially long-range planning such as for assignments or exams that are due in several weeks or even months (Gelbar et al. 2014; Gobbo and Shmulsky 2014; Pinder-Amaker 2014). These findings are supported by teacher observations, since both students with ASD and their teachers observe difficulties in over-focusing on details, planning, and time management, especially when students have to submit several essays per term, and when deadlines cover an extended period of time (Knott and Taylor 2014).

Other challenges experienced by students with ASD border on the cognitive and behavioural level, and are related to impaired TOM, social-emotional deficits, and communicational problems. Beardon et al. (2009) showed that as many as $40 \%$ of students with ASD report group work, social interaction, and communicating with peers as the most common problems they encounter. This fits with several other studies in which students with ASD mentioned group work as one of the most challenging aspects of student life, especially when groups are bigger or when group discussion is required (Gobbo and Shmulsky 2014; Knott and Taylor 2014). In addition, students with ASD often see fellow students as being less conscientious, leading to situations in which the student with ASD does most of the group work (Knott and Taylor 2014). This, in turn, causes frustration and feelings of injustice. Other emotional problems present in ASD are high levels of stress, depression, and anxiety (Ghaziuddin et al. 2002; Gillott and Standen 2007; Kim et al. 2000; Sterling et al. 2008). Transitioning from secondary education to university brings about stress and anxiety in students with ASD (PinderAmaker 2014), and teachers report that activities such as group work appear to increase anxiety in these students, which has a negative effect on symptom severity and well-being (Gobbo and Shmulsky 2014). The discussed problems many students with ASD face appear to have a negative impact on academic performance as well. Students with disabilities in general, including ASD, have a higher dropout and perform worse (Dunn et al. 2004; Wei et al. 2014). In addition, longitudinal data showed that starting college or university does not necessarily translate into success and graduation in students with ASD, since this specific group has higher attrition rates than TD students (Wei et al. 2014).

Although a small number of studies examined the problems students with ASD face, no research to date has looked into problems, benefits, and performance of students with 
ASD in specific forms of education, even though findings from such a study could have major implications in choice of university by prospective students. Therefore, the current article examines whether the characteristics of a form of constructivist learning, problem-based learning (PBL), are suitable to the needs of students with ASD.

Constructivist theories emphasise several constructs of learning that originate in the ideas of Piaget and Vygotsky (Slavin 2005). Most importantly, they emphasise selfregulated discovery learning, meaning that the learner should discover and construct new information mostly by himself or herself, and not via direct instruction. In that process of discovering information, the learner notices when new information does not fit with old information, and when old ideas need to be revised. Teachers offer help when students are not able to understand something, but this help comes in the form of mediated learning or scaffolding. Constructivism also emphasises a cooperative learning component: learning is enhanced by discussing information with others. Lastly, constructivist learning encompasses top-down processing: students start with complex problems, and discover step by step the basic abilities needed to tackle that problem. Together, these constructs make that learners play a much more active role in their learning process compared to most traditional curricula.

PBL is a specific form of constructivist learning that originates in the 1960s, and was meant to increase flexible knowledge, problem-solving skills, and motivation (Loyens et al. 2012). In most PBL curricula, students meet in small groups of approximately 10 students twice a week for 2 to 3 hours. Learning starts with a pre-discussion, in which students discuss a complex, ill-structured problem that needs an answer or explanation. They discuss what they already know about the subject matter, and together form a tentative explanation and learning issues, questions concerning the subject matter that are intended to guide the search for information that will happen in the second phase. During this second phase, the students individually study the problem for a few days. They then meet again in the post-discussion meeting, in which they critically evaluate the studied information and discuss how this information helps in answering the learning issues (Loyens et al. 2012; Schmidt et al. 2007). During the meetings, a tutor is present, who can help the students by giving suggestions when they get stuck or when they do not seem to go into the right direction. However, the tutor's role is to offer guidance, and not direct instruction (Schmidt et al. 2007). Thereby, PBL attempts to create a learning environment in which students learn in the context of meaningful problems, and in which they activate prior information, acquire new information, and actively process this (Norman and Schmidt 1992; Schmidt et al. 2007). The basic ideas PBL holds therefore closely match the basic constructivist ideas: learning should be a constructive process, a self-directed process, a collaborative process, and a contextual process (Dolmans et al. 2005).
The constructive learning assumption holds that learning is done best by actively processing information, and that by constructing or reconstructing your knowledge networks, information will be retained better (Capon and Kuhn 2004; Dolmans et al. 2005). This constructive process is e.g. reflected in the independent search for information. At first sight, it seems like this offers less support than traditional curricula. However, PBL is more structured than it would seem. Most PBL curricula provide a list of selected study sources students can use. Also, the learning issues provide structure: while it is not clear on beforehand which exact chapters need to be studied, the goal of what one should know at the end is clear. In traditional curricula, this is reversed: the student knows what to study, but the end goal of knowledge is unknown. In addition, the searching and structuring of information that is inherent to PBL requires detailed working, which generally fits well with the cognitive structure of students with ASD (Gobbo and Shmulsky 2014; Knott and Taylor 2014). Lastly, many students with ASD are very driven to discover new information, figure things out, and solve problems (Gobbo and Shmulsky 2014). A good PBL student has intrinsic motivation to learn, and students with ASD often possess this quality. Two possible problems concerning learning as a constructive process arise from the weak central coherence and the focus on bottom-up processing that many students with ASD show (Frith and Happé 1994; Gobbo and Shmulsky 2014; Slavin 2005). These cognitive characteristics often seen in ASD are opposite to the intrinsic top-down component of PBL, in which you start with the highest-order element (the learning issue) and are required to retrieve smaller pieces of information that consequently have to be structured into one big picture to answer the learning issues. One of the problems students with ASD could encounter is getting lost in the details, and not being able to form the integrated whole that is needed to answer the learning issues. However, the structure PBL offers also provides a good practice environment for forming the bigger picture. The learning issues in PBL are specifically designed to help students with collecting information and constructing it into a whole. In addition, starting the search with a central question could help in ordering the found pieces of information. This way, PBL could provide a safe and structured practice environment for both top-down processing and forming a stronger central coherence.

The second assumption states that learning should be a selfdirected process. This assumption is related to the knowledgedeprivation hypothesis, which assumes that when students read problems, they get motivated to obtain more knowledge in order to understand and answer the problem. Therefore, self-directed learning contains a motivational aspect: the desire to know causes students to be more willing to play an active role in planning, monitoring, and evaluating their learning process (Dolmans et al. 2005; Slavin 2005). Although 
self-directed learning implies much planning and self-regulation, the guidance and structure offered in PBL is extensive compared to that of traditional curricula. First of all, PBL offers the student a relatively strict schedule. Students are obligated to meet at regular days and times that are fixed for the whole course or even the whole year, thereby providing a fixed week structure. While this can be beneficial for all students, it is especially helpful for students who have difficulty structuring their time themselves. Second, PBL works with proximal deadlines. Exam dates and essay deadlines cover a maximum of 5 weeks, and during that time even more proximal deadlines of a few days are set because students need to prepare for the tutorial group meeting once or twice a week. This makes it easier for students to plan, because planning a few days of studying ahead may be less difficult than planning a few weeks ahead. Courses in traditional curricula last longer, have more distant deadlines, and do often not have mandatory meetings for which preparation is required. In addition, PBL courses are given one at a time. Since many students with ASD report having difficulty with long-term deadlines (Gelbar et al. 2014) and with shifting between different courses (Gobbo and Shmulsky 2014; Knott and Taylor 2014), PBL could especially suit them.

The third PBL proposition is that learning should be a collaborative process. This assumption has his roots in the constructivist idea that explaining concepts to others helps in understanding and retaining the information yourself (Van Blankenstein et al. 2011). Looking at mind blindness, which is often observed in ASD, discussing information in a group might be a challenge for students scoring high on the autism spectrum: the focus on social learning, collaboration, and discussing information could be a difficult, tiring, stimulusoverloading, and stress-inducing experience. On the other hand, because groups in PBL are small, students have a better chance to get to know each other. When group work is required, e.g. for an essay, being already familiar with group members could be an advantage compared to the weaker social ties that are developed in traditional lecture-based curricula. Finally, working together in tutorial groups and being allowed to talk about ideas may be less distracting than passively listening to lectures. This may be especially beneficial for students with ASD who report getting distracted easily (Gelbar et al. 2014). In addition, many individuals with ASD like to talk out loud, because it helps in organising their thinking (Grandin and Johnson 2005). Therefore, having the opportunity to talk about ideas in tutorial groups might also fit with the cognitive setup of many individuals with ASD.

The fourth proposition is that learning should be a contextual process. This assumption is based on the idea that all learning is situated, and that by looking at problems from multiple perspectives, transfer increases (Dolmans et al. 2005). Since knowledge is often only useful if it can be transferred to other contexts, transfer serves as an important end goal of most educational practices. In relation to ASD, the specific way PBL tries to achieve knowledge transfer could form a problem. Impaired TOM and intersubjectivity are often observed in ASD, which means that students with ASD might experience difficulties in looking at problems from multiple perspectives. This might especially be true for students who took more exact science classes in secondary school, such as physics and chemistry, in which there is less need to consider multiple viewpoints than is the case in subjects like history. A related problem concerns the general ability to generalise information. Mirenda and Donnellan (1987) stated that individuals with ASD often have difficulties in generalising new information to novel environments. This observation can be explained by Plaisted's (2001) reduced generalisation hypothesis, which states that ASD is characterised by reduced processing of the similarities between stimuli and situations. The concepts that individuals with ASD use are narrower, and have sharper, more clearly defined boundaries, making individuals with ASD generally speaking better at processing divergent than shared features. This might pose a problem in PBL if the change from book to problem is too large. A more gradual change in context might be useful in such cases, which is also the biggest benefit PBL could offer. Because all forms of education ultimately focus on transfer, a reduced ability to generalise forms a problem in any form of education. The advantage PBL offers is a practice environment in which the degree of required transfer from study material to real world can be manipulated by adjusting the learning issues. Practicing transfer this way might provide an advantage as compared to more rigid forms of education. After all, the problems that are used in PBL are specifically designed to show multiple perspectives and to elicit discussion.

Since the implementation of PBL, research has tried to form a coherent view of its benefits, especially compared to traditional lecture-based education. Criticism on PBL mostly focuses on the assumed non-fit between the human cognitive architecture and the idea of minimal guidance. Kirschner et al. (2006) stated that although minimally guided instructional approaches are intuitively appealing, they ignore that beginning learners require more direct instruction. The benefits of minimal guidance would only occur when learners already have a sufficient prior knowledge base to guide themselves. Schmidt et al. (2007) rebutted this view by stating that PBL does not equal minimally guided instruction, but that the problems and guidance offer students optimal conditions to discover information themselves. Scaffolding, an important constructivist principle, does not mean that guidance is 'minimal'.

The positive effects of PBL are well-documented for TD students, with important outcomes being higher intrinsic motivation for studying, enhanced interest in the subject matter, higher satisfaction with contact with teachers and fellow students, and higher satisfaction with integration of knowledge in practice (Loyens et al. 2012; Norman and Schmidt 1992). In 
addition, PBL students have a higher long-term retention of the learned material (De Grave et al. 2001; Schmidt et al. 2012). Besides enhanced knowledge, studies also indicated that PBL improves practical skills, showing increases in selfdirected learning skills, social skills, scientific thinking skills, clinical skills, and critical thinking skills (Loyens et al. 2012; Norman and Schmidt 1992; Strobel and Van Barneveld 2009). Lastly, students in PBL graduate faster, have shorter study stops, and have less dropout during their studies compared to students from traditional curricula (Schmidt et al. 2009; Severiens and Schmidt 2009; Susarla et al. 2003). This lower dropout can also explain why some studies fail to find an effect of PBL on grades. Students in PBL curricula do have higher knowledge and skills, but this effect is masked by the lower dropout of especially weaker students (Schmidt et al. 2012). Students who drop out in traditional curricula are often retained in PBL. Therefore, the masking effect of attrition bias could account for failing to find an effect of PBL on grades.

Because to date no research has been done on the fit between ASD characteristics and PBL features, the described ideas about how students scoring high on the autism spectrum would perform in PBL are mostly speculative. They are based on linking research that was done on students with ASD and PBL separately. Therefore, the present study aims to be an exploratory study on the fit between ASD and PBL. A new questionnaire was developed to assess problems and benefits students could experience in PBL. Performance levels were determined by averaging exam grades. ASD symptomatology was measured with the use of the Autism-Spectrum Quotient (AQ, Baron-Cohen et al. 2001). This questionnaire builds upon the autism spectrum hypothesis, stating that ASD characteristics lie on a continuum that ranges from TD individuals to individuals diagnosed with ASD (Baron-Cohen et al. 2001; Wing 1988). Across this continuum, individuals show different levels of autistic traits. Therefore, not only responses from individuals belonging to the clinical population but responses from everyone on this broad spectrum offer valuable inside into ASD.

With the use of the newly developed questionnaire, the performance measure, and the AQ, the present study examined whether higher ASD symptomatology is predictive of performance and experienced problems and benefits in PBL curricula.

\section{Method}

\section{Participants}

Participants were students of faculties using the PBL system: Law (law, tax law, criminology) and Social Sciences (psychology, sociology, pedagogical sciences). Students were recruited via the online message board of the university, via faculty- related social media, and via the psychology course credit system. In total, 134 responses were collected. A number of $n=27$ respondents were excluded for missing grades, doing the non-PBL law and economics program, doing the year for the second time, or a combination of these characteristics. The final sample consisted of $n=107$ students of the Faculty of Law $(n=22)$ and the Faculty of Social Sciences $(n=85)$, with a mean age of $M=20.55(S D=2.13)$. Gender was relatively balanced across the sample, with $n=42$ male and $n=65$ female respondents. Most students were in their first year $(n=73)$, with 23 second-year, 7 third-year, and 4 fourthyear students. In addition, most studied psychology $(n=83)$, with 13 studying law, 5 criminology, 4 tax law, 1 sociology, and 1 studying pedagogical sciences. None of the participants had received an official ASD diagnosis. Informed consent was obtained from all participants included in the study, and all procedures performed were in accordance with the ethical standards of the institutional research committee and with the 1964 Helsinki Declaration and its later amendments.

\section{Procedure}

Responses were collected online via Qualtrics. First, an introductory text briefly explained the aim of the study. Then, the confidentiality regulations were explained, and the student could give permission for using his or her data for scientific purposes. In case of no consent, the survey automatically ended. Then, the student was asked to report his or her main study, study year, age, and gender. Then, the AQ and the ASD-PBL Fit Questionnaire were explained and administered, followed by a question concerning mean grade and permission to have the grade checked against university records. Lastly, the participant was asked about being diagnosed with ASD. Then, he or she was thanked for participating, and was given contact details of the experimenter in case of further questions.

\section{Measures}

ASD-PBL Fit Questionnaire Because no measures existed to examine the benefits and problems of students in a PBL curriculum, a new questionnaire consisting of 40 questions was created. All questions were answered on a 4-point Likert scale: seldom or never, sometimes, often, and almost always. For each of the four main aspects of PBL (constructive, selfdirected, collaborative, and contextual learning), five items were used for registering problems and five items were used for registering benefits. This led to two scores for each participant, a problem score and a benefit-score, both containing four sub-scales. The minimum score on both the problem part and the benefit part of the questionnaire was 20 , with a maximum of 80 , the latter indicating that the student experienced the full range of problems or benefits PBL could give. For each sub-scale, the minimum score was 5 , and the maximum 
score 20. Cronbach's alpha was $\alpha=0.81$ for the composite problem score, $\alpha=0.61$ for the constructive learning problem score, $\alpha=0.44$ for the self-directed learning problem score, $\alpha=0.66$ for the collaborative learning problem score, and $\alpha=0.78$ for the contextual learning problem score. Cronbach's alpha was $\alpha=0.90$ for the composite benefitscore, $\alpha=0.71$ for the constructive learning benefit-score, $\alpha=0.71$ for the self-directed learning benefit-score, $\alpha=0.79$ for the collaborative learning benefit-score, and $\alpha=0.74$ for the contextual learning benefit-score. To examine the factor structure, a principal component analysis (PCA) with direct oblimin rotation was run on both scales. The correlation patterns of the problem-scale were compact, the items were sufficiently correlated, and multicollinearity was not a problem. However, it was difficult to distinguish the four subscales: the theorised four-component structure (explaining $53.46 \%$ of the variance) was not optimal, and only the constructive and contextual learning component could be easily separated based on the structure matrix. The correlation patterns of the benefit scale were also compact, the items were sufficiently correlated, and multicollinearity was again not a problem. Extracting four components explained 59.89\% of variance, which was higher than the amount of variance explained by the four-factor extraction of the problem-scale. Nonetheless, it was again difficult to distinguish the theorised four-component structure. An English translation of the questionnaire is available upon request.

Autism-Spectrum Quotient The Autism-Spectrum Quotient (AQ, Baron-Cohen et al. 2001) is a continuous and quantitative self-report measure of autistic traits in adults of normal intelligence. The questionnaire consists of 50 questions, divided into 5 sub-scales of 10 items each: social skill, attention switching, attention to detail, communication, and imagination. Items are answered on a 4-point Likert scale: definitely agree, slightly agree, slightly disagree, and definitely disagree. Both the original English version of the test and its Dutch translation showed satisfactory psychometric properties (Baron-Cohen et al. 2001; Hoekstra et al. 2008). The original scoring scheme as proposed by Baron-Cohen et al. (2001) is binary, ignoring the degree of agreement or disagreement. In line with Austin (2005) and Hoekstra et al. (2008), we included all four levels in scoring, which yields higher internal consistency and test-retest reliabilities than binary scoring (Stevenson and Hart 2017), and which has been shown to improve the reliable range of measurement significantly (Murray et al. 2016). This resulted in a minimum total score of 50 (the individual reports having no autistic traits) and a maximum score of 200 (the individual reports having the full range of autistic traits). As could be expected based on score variability, reliability was better when using the full-range scoring scheme. Cronbach's alpha was $\alpha=0.86$ for the composite score (as opposed to $\alpha=0.80$ using binary scoring), $\alpha=0.78(\alpha=0.73)$ for social skill, $\alpha=0.72(\alpha=0.60)$ for attention switching, $\alpha=0.77(\alpha=0.67)$ for attention to detail, $\alpha=0.59(\alpha=0.43)$ for communication, and $\alpha=0.57$ $(\alpha=0.39)$ for imagination.

Performance Performance was measured by asking the students about their rounded mean exam grade, which was checked against university records.

\section{Data Analyses}

Because the measurement of problems and benefits of PBL and autistic traits is of the same type (self-report), there is a risk of common method bias (CMB), in which variance in the data is attributable to the measurement method instead of the constructs that the measures are hypothesised to represent (Podsakoff and Organ 1986; Podsakoff et al. 2003, 2012). This can inflate or deflate correlations, thus leading to type I and II errors (Podsakoff et al. 2003, 2012; Williams and Brown 1994). Therefore, we first tested for CMB with the use of Harman's single-factor test.

Then, the descriptive statistics of the ASD-PBL Fit Questionnaire, the AQ, and the performance measure were calculated. Then, the measures were combined to examine the relationship between ASD symptomatology, performance, and experienced problems and benefits in PBL. To this end, six hierarchical multiple regression analyses (HMRAs) and one correlation analysis were performed. All HMRAs controlled for the influence of age and gender. We statistically controlled for experiment-wise error. The first HMRA regressed experienced problems on AQ-score; the second regressed experienced benefits on AQ-score; and the third regressed performance on AQ-score. The correlation analysis then examined the relationship between experienced problems and benefits. The last three HMRAs regressed performance on experienced problems and benefits, both together and separately.

\section{Results}

All descriptives and correlations between the variables are shown in Table 1.

\section{Common Method Bias (CMB)}

All items (measuring latent variables) were loaded into an exploratory factory analysis. A fixed number of one factor was extracted. This was done separately for the relationship between the problem-scale items and the AQ items on the one hand, and the benefit scale items and the AQ items on the other hand. The unrotated factor solutions 
Table 1 Descriptives and Pearson's correlation matrix of all variables

\begin{tabular}{|c|c|c|c|c|c|c|c|c|c|}
\hline & & M & SD & 1 & 2 & 3 & 4 & 5 & 6 \\
\hline 1 & Age & 20.55 & 2.13 & 1 & & & & & \\
\hline 2 & Gender & 1.61 & 0.49 & -0.16 & 1 & & & & \\
\hline 3 & ASD symptomatology & 100.93 & 14.87 & 0.13 & -0.09 & 1 & & & \\
\hline 4 & Experienced problems & 40.79 & 7.70 & $0.28 * *$ & -0.13 & $0.51 * *$ & 1 & & \\
\hline 5 & Experienced benefits & 58.01 & 10.36 & $-0.40 * *$ & 0.10 & $-0.32 * *$ & $-0.69 * *$ & 1 & \\
\hline 6 & Performance & 6.59 & 0.96 & -0.01 & -0.07 & -0.07 & $-0.20^{*}$ & -0.01 & 1 \\
\hline
\end{tabular}

were examined. For the analysis involving the problemscale items and the AQ items, $14.51 \%$ of variance was explained by the single factor. For the analysis involving the benefit scale items and the AQ items, this was $15.28 \%$. Since both values were below $50 \%$, we concluded that $\mathrm{CMB}$ was not an issue.

\section{The ASD-PBL Fit Questionnaire}

The mean problem-score was $M=40.79(S D=7.70)$, range 26-66. The mean benefit-score was $M=58.01(S D=10.36)$, range 30-77. Both distributions were approximately normal as determined by visual inspection of the normal Q-Q plot. The difference between the two scores was significant: participants reported to experience more benefits than problems from working in PBL, $t(106)=10.70, p<.001, \eta_{p}^{2}=.52$. The problem-score and the benefit-score did both not differ between humanities and social sciences students (problemscore: $t(27.44)=0.22, p=.825, \eta_{p}^{2}<.01$; benefit-score: $\left.t(25.27)=1.61, p=.120, \eta_{p}^{2}=.04\right)$ and between men and women (problem-score: $t(105)=1.33, p=.185, \eta_{p}^{2}=.02$; benefit-score: $\left.t(105)=1.14, p=.258, \eta_{p}^{2}=.01\right)$. All mean (SD) Fit Questionnaire scores and sub-scores are shown in Table 2.

\section{The Autism-Spectrum Quotient}

The mean AQ-score was $M=100.93(S D=14.87)$, range 66144. The distribution was approximately normal as determined by visual inspection of the normal Q-Q plot. AQscore did not differ between humanities and social sciences students $\left(t(105)=0.52, p=.602, \eta_{p}^{2}<.01\right)$ and between men and women $\left(t(105)=0.88, p=.381, \eta_{p}^{2}<.01\right)$. One participant scored above the clinical cut-off score of 32 (BaronCohen et al. 2001) as determined by the binary scoring scheme (present range 2-33 out of $0-50$ ). All mean (SD) AQ-scores and sub-scores are shown in Table 3.

\section{Performance (grade)}

The mean rounded self-reported grade of all participants on a $1-10$ rating scale was $M=6.59(S D=0.96)$, range $3-8$. The distribution was left-skewed as determined by visual inspection of the normal Q-Q plot: most individuals scored a 7 (45 cases), followed by a 6 (37 cases) or an 8 (16 cases). However, 9 students scored low, namely, a 3 ( 1 case), a 4 (3 cases), or a 5 ( 5 cases). This score pattern created a left skew. Grade did not differ between humanities and social sciences students $\left(t(105)=1.26, p=.211, \eta_{p}^{2}=.01\right)$ and between men and women $\left(t(105)=0.67, p=.503, \eta_{p}^{2}<.01\right)$. In 98 cases, both the student and the associated faculty at which he or she studied gave permission to have the grade checked in the university grade recording system. Taking missing grades into account, the rounded self-reported grade did not significantly differ from the checked grade, $t(75)=0.79, p=.432$, $\eta_{p}^{2}=.01$. Therefore, the rounded self-reported grades of all 107 participants were used in the analyses.

\section{Combining the Measures}

Figure 1 summarises the found relationships between ASD symptomatology, problems, benefits, and performance in PBL. Significant relationships are flagged (in asterisk). The analyses belonging to all shown relationships are reported below. A summary of the outcome of the main regression analyses is provided in Table 4. The analyses identified one outlier, namely, a participant with an AQ-score of 144. All analyses were also run with this outlier excluded. None of the main conclusions changed.

Does ASD Symptomatology Predict Experiencing Problems in PBL? The HMRA showed that age and gender together significantly contributed to the regression model, $F(2,104)=4.70, p=.011, R^{2}=.08$. This was due to the influence of age $(\beta=0.26, t=2.74, p=.007)$ and not gender $(\beta=-0.09, t=-0.91, p=.363)$. Controlling for the influence of age and gender, AQ-score significantly predicted 
Table 2 Mean (SD) fit questionnaire scores for the problem-scale and benefit-scale per study and gender

\begin{tabular}{|c|c|c|c|c|c|}
\hline & & & Men & Women & Total \\
\hline \multirow[t]{11}{*}{ Problems } & \multirow[t]{5}{*}{ Social sciences } & Constructive process & $9.84(1.90)$ & $10.45(2.32)$ & $10.18(2.15)$ \\
\hline & & Self-directed process & $12.05(2.25)$ & $11.19(2.49)$ & $11.58(2.41)$ \\
\hline & & Collaborative process & $9.37(2.19)$ & $9.09(3.15)$ & $9.21(2.75)$ \\
\hline & & Contextual process & $10.29(2.57)$ & $9.28(2.74)$ & $9.73(2.70)$ \\
\hline & & Total & $41.55(5.71)$ & $40.00(8.20)$ & $40.69(7.20)$ \\
\hline & \multirow[t]{6}{*}{ Humanities } & Constructive process & $9.75(1.50)$ & $8.94(2.41)$ & $9.09(2.27)$ \\
\hline & & Self-directed process & $15.00(1.83)$ & $11.50(2.46)$ & $12.14(2.70)$ \\
\hline & & Collaborative process & $10.25(3.86)$ & $9.44(3.20)$ & $9.59(3.25)$ \\
\hline & & Contextual process & $11.50(4.93)$ & $10.11(3.64)$ & $10.36(3.81)$ \\
\hline & & Total & $46.50(10.28)$ & $40.00(9.30)$ & $41.18(9.58)$ \\
\hline & & Total & $42.02(6.27)$ & $40.00(8.44)$ & $40.79(7.70)$ \\
\hline \multirow[t]{11}{*}{ Benefits } & \multirow[t]{5}{*}{ Social sciences } & Constructive process & $12.92(2.55)$ & $13.72(2.84)$ & $13.36(2.73)$ \\
\hline & & Self-directed process & $15.71(2.95)$ & $16.49(2.48)$ & $16.14(2.71)$ \\
\hline & & Collaborative process & $13.71(2.84)$ & $14.83(2.94)$ & $14.33(2.93)$ \\
\hline & & Contextual process & $14.79(1.95)$ & $15.60(2.65)$ & $15.24(2.38)$ \\
\hline & & Total & $57.13(7.72)$ & $60.64(9.46)$ & $59.07(8.85)$ \\
\hline & \multirow[t]{6}{*}{ Humanities } & Constructive process & $11.50(5.00)$ & $11.83(3.17)$ & $11.77(3.42)$ \\
\hline & & Self-directed process & 14.75 (4.99) & $15.28(4.00)$ & $15.18(4.07)$ \\
\hline & & Collaborative process & $12.00(4.97)$ & $12.67(4.65)$ & $12.55(4.60)$ \\
\hline & & Contextual process & $13.25(4.57)$ & $14.67(3.71)$ & $14.41(3.80)$ \\
\hline & & Total & $51.50(18.73)$ & $54.44(13.82)$ & $53.91(14.36)$ \\
\hline & & Total & $56.60(9.07)$ & $58.92(11.09)$ & $58.01(10.36)$ \\
\hline
\end{tabular}

experienced problems in PBL: participants with higher reported ASD symptomatology reported experiencing more problems, $F(3,103)=15.24, p<.001, R^{2}=.31$. Including AQscore in the model explained an additional $22.46 \%$ of variance, which was significant, $F_{\text {change }}(1,103)=33.40, p<.001$. This relationship between the total PBL problem-score and the AQ-score is shown in Fig. 2 (dashed line). Table 4 shows the outcome of the main regression. Table 5 shows the results of the regressions on both the total scale and the sub-scales. Especially variance in problems concerning the collaborative learning element was well explained by ASD symptomatology, although the variance in the contextual, self-directive, and constructive learning element could also be explained by ASD symptomatology.

Table 3 Mean (SD) AQ-Scores per study and gender

\begin{tabular}{llccc}
\hline & & Men & Women & Total \\
\hline Social sciences & Social skill & $18.45(3.99)$ & $19.23(5.32)$ & $18.88(4.76)$ \\
& Attention switching & $22.26(3.94)$ & $22.43(4.67)$ & $22.35(4.34)$ \\
& Attention to detail & $23.21(4.95)$ & $21.60(5.09)$ & $22.32(5.06)$ \\
& Communication & $19.03(3.39)$ & $18.15(4.04)$ & $18.54(3.77)$ \\
& Imagination & $19.68(4.01)$ & $17.45(3.44)$ & $18.45(3.85)$ \\
Humanities & Total & $102.63(12.99)$ & $98.85(16.27)$ & $100.54(14.93)$ \\
& Social skill & $18.00(4.76)$ & $18.67(3.99)$ & $18.55(4.02)$ \\
& Attention switching & $21.00(4.32)$ & $21.83(5.24)$ & $21.68(1.07)$ \\
Total & Attention to detail & $23.00(6.48)$ & $24.00(5.16)$ & $19.06(3.02)$ \\
\hline
\end{tabular}




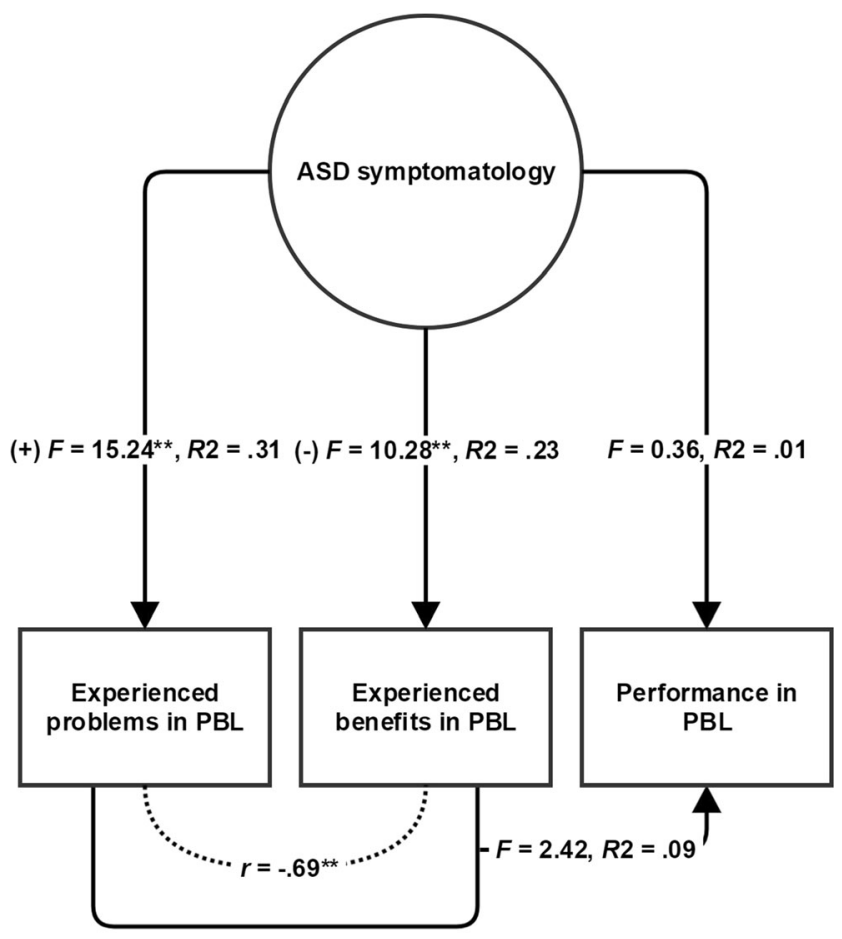

${ }^{* *}$ is significant at .01 level

Fig. 1 Relationships between ASD symptomatology, problems, benefits, and performance in PBL

\section{Does ASD Symptomatology Predict Experiencing Benefits} in PBL? The HMRA showed that age and gender together significantly contributed to the regression model, $F(2$, 104) $=9.87, p<.001, R^{2}=.16$. This was again due to the influence of age $(\beta=-0.39, t=-4.27, p<.001)$ and not gender $(\beta=0.05, t=0.52, p=.603)$. Controlling for the influence of age and gender, AQ-score significantly predicted experienced benefits in PBL: participants with higher reported ASD symptomatology reported experiencing less benefits, $F(3,103)=10.28, p<.001, R^{2}=.23$. Including AQ-score in the model explained an additional $7.09 \%$ of variance, which was significant, $F_{\text {change }}(1,103)=9.49, p=.003$. This relationship between the total PBL benefit-score and the AQ-score is shown in Fig. 2 (solid line). Table 4 shows the outcome of the main regression. Table 5 shows the results of the regressions on both the total scale and the sub-scales. Especially variance in benefits concerning the contextual learning element was well explained by ASD symptomatology, although the variance in the collaborative, constructive, and self-directive learning element could also be explained by ASD symptomatology.

Does ASD Symptomatology Predict Performance in PBL? The HMRA showed that age and gender together did not significantly contribute to the regression model, $F(2$,
104) $=0.25, p=.777, R^{2}<.01$. Controlling for the influence of age and gender, AQ-score was not predictive of performance, $F(3,103)=0.36, p=.784, R^{2}=.01$. The increase in explained variance after adding AQ-score to the model $(0.54 \%)$ was not significant, $F_{\text {change }}(1,103)=0.57$, $p=.453$. Table 4 shows the outcome of the main regression.

Are Experienced Problems in PBL Related to Experienced Benefits in PBL? The correlation analysis showed that the total problem-score and the total benefit-score were negatively related to each other: experiencing more problems was related to experiencing fewer benefits, $r(105)=-.69, p<.001$.

Do Experienced Problems and Benefits in PBL Predict Performance? The HMRA showed that, controlling for age and gender, the experienced problems and benefits did not significantly predict performance either together $(F(4$, $\left.102)=2.42, p=.053, R^{2}=.09\right)$ or separately $(F(3$, $103)=1.73, p=.166, R^{2}=.05$ for problems; $F(3$, $103)=0.17, p=.916, R^{2}<.01$ for benefits), although the effect size for the combined prediction was medium. Table 4 shows the outcome of the main regression.

\section{Discussion}

The present study examined the relationship between ASD symptomatology, problems, benefits, and performance in PBL. Results showed that a higher AQ-score predicted experiencing more problems and fewer benefits of PBL. However, AQ-score was not related to performance. The problem-score and benefit-score were negatively correlated: experiencing more problems was related to experiencing fewer benefits.

Some specific findings concerning experienced problems and benefits are in line with previous research. On the problem-scale, higher ASD symptomatology had the strongest impact on the collaborative learning element. This is in line with the hypothesis that this constructivist idea might be the biggest challenge students scoring high on the autism spectrum face. It is also in line with previous research showing that students with ASD often report experiencing difficulty with group work and social communication in class (Gobbo and Shmulsky 2014; Knott and Taylor 2014). The biggest loss in benefits as a result of ASD symptomatology was on the contextual learning element. This is in line with Plaisted's (2001) reduced generalisation hypothesis and other findings concerning the difficulty many individuals with ASD experience in generalising information (Mirenda and Donnellan 1987).

Focusing on the main question, what do the present findings say about the ASD-PBL fit? The finding that students with more autistic traits experience more problems and fewer 
Table 4 Outcome of the hierarchical multiple regression models

\begin{tabular}{|c|c|c|c|c|c|}
\hline Model & Variable & $B$ model 1 & $B$ model 2 & Model 2 & 95\% CI model 2 \\
\hline \multirow[t]{8}{*}{ Predicting problems from AQ } & Constant & $23.62 * *$ & 2.01 & & {$[-13.49,17.50]$} \\
\hline & Age & $0.94 * *$ & $0.74 *$ & & {$[0.14,1.34]$} \\
\hline & Gender & -1.37 & -0.87 & & {$[-3.46,1.73]$} \\
\hline & $\mathrm{AQ}$ & & $0.25 * *$ & & {$[0.16,0.33]$} \\
\hline & $R^{2}$ & 0.08 & & 0.31 & \\
\hline & $F$ & $4.70 *$ & & $15.24 * *$ & \\
\hline & $\Delta R^{2}$ & & & 0.23 & \\
\hline & $\Delta F$ & & & $33.40 * *$ & \\
\hline \multirow[t]{8}{*}{ Predicting benefits from AQ } & Constant & $95.30 * *$ & $111.65 * *$ & & {$[89.66,133.63]$} \\
\hline & Age & $-1.89 * *$ & $-1.74 * *$ & & {$[-2.56,-0.89]$} \\
\hline & Gender & 1.00 & 0.63 & & {$[-3.05,4.30]$} \\
\hline & AQ & & $-0.19 * *$ & & {$[-0.31,-0.07]$} \\
\hline & $R^{2}$ & 0.16 & & 0.23 & \\
\hline & $F$ & $9.87 * *$ & & $10.28 * *$ & \\
\hline & $\Delta R^{2}$ & & & 0.07 & \\
\hline & $\Delta F$ & & & $9.49 * *$ & \\
\hline \multirow[t]{8}{*}{ Predicting grade from AQ } & Constant & $7.028 * *$ & $7.45^{* *}$ & & {$[5.15,9.76]$} \\
\hline & Age & -0.01 & -0.01 & & {$[-0.10,0.08]$} \\
\hline & Gender & -0.14 & -0.15 & & {$[-0.53,0.24]$} \\
\hline & AQ & & -0.01 & & {$[-0.02,0.01]$} \\
\hline & $R^{2}$ & $<0.01$ & & 0.01 & \\
\hline & $F$ & 0.25 & & 0.36 & \\
\hline & $\Delta R^{2}$ & & & 0.01 & \\
\hline & $\Delta F$ & & & 0.57 & \\
\hline \multirow[t]{9}{*}{ Predicting grade from benefits and problems } & Constant & $7.028 * *$ & & $10.73 * *$ & {$[7.16,14.29]$} \\
\hline & Age & -0.01 & & -0.01 & {$[-0.11,0.08]$} \\
\hline & Gender & -0.14 & & -0.18 & {$[-0.55,0.20]$} \\
\hline & Problems & & & $-0.05 * *$ & {$[-0.08,-0.02]$} \\
\hline & Benefits & & & $-0.03 *$ & {$[-0.05,<-0.01]$} \\
\hline & $R^{2}$ & 0.01 & & 0.09 & \\
\hline & $F$ & 0.25 & & 2.42 & \\
\hline & $\Delta R^{2}$ & & & 0.08 & \\
\hline & $\Delta F$ & & & $4.57 *$ & \\
\hline
\end{tabular}

$N=107$

$C I$ confidence interval

$* p<.05 ; * * p<.01$

benefits of PBL seems to suggest that PBL is not a good fit for students with ASD. However, this conclusion is premature. First, the current results were not directly compared to traditional lecture-based curricula. Previous findings (Gelbar et al. 2014; Gobbo and Shmulsky 2014; Knott and Taylor 2014; Mulder and Cashin 2014; Pinder-Amaker 2014) suggest that students with ASD do report problems in traditional curricula, and based on the current findings, it is not possible to say whether the problems experienced in PBL are higher or lower than the problems experienced in traditional curricula. For instance, if the relationship between ASD symptomatology and experienced problems is stronger for traditional than PBL curricula, PBL would still be a better fit, despite the fact that students scoring high on autistic traits report having more problems than students scoring low on the autism spectrum. Second, more problems and less benefits do not automatically mean large problems and small benefits; the problems are just larger and the benefits smaller than those of students with less autistic traits, with no indication of the magnitude of those problems and benefits. Third, the performance of the present 


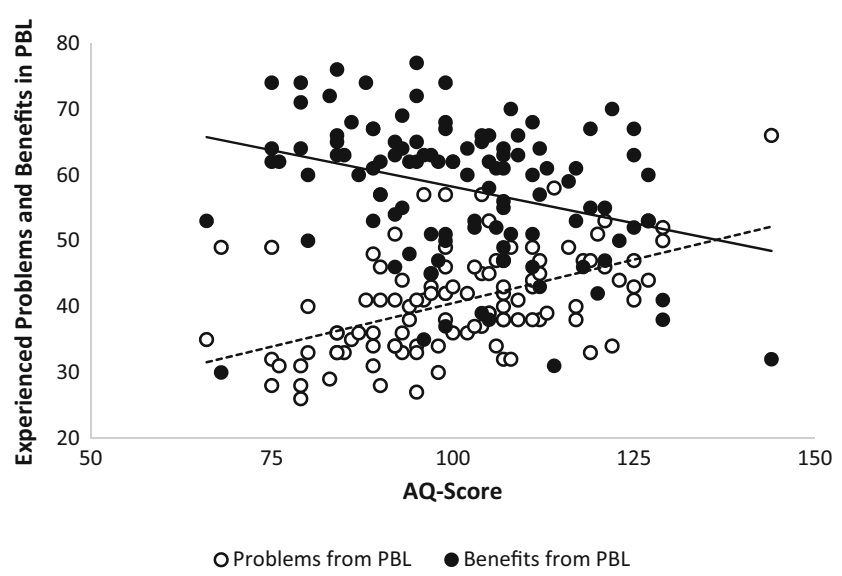

Fig. 2 Relationship between the PBL benefit-score (solid line) and PBL problem-score (dashed line) and the AQ-score

sample of PBL students was not related to ASD symptomatology. Whereas previous findings indicate lower performance of students with ASD in traditional university curricula (Dunn et al. 2004; Wei et al. 2014), PBL apparently eliminates this, since ASD symptomatology is not related to grades. This suggests that features of PBL might actually fit well with the characteristics of ASD.

There are multiple possible explanations for the found discrepancy between the reported problems and benefits on the one hand and performance on the other hand. First, it might be the result of a methodological characteristic of the study: students were asked to report their rounded mean grade. This rounding might have made the measure less sensitive. However, the percentage explained variance was that small that only the effect of the rounding procedure is unlikely to be strong enough to have caused the non-effect of AQ-score on performance.

Another possible methodological explanation concerns an inevitability: experienced problems and benefits are experienced, and not objective measures. Therefore, the possibility exists that students with higher ASD symptomatology indeed feel like PBL brings them more problems and fewer benefits than it does for students scoring low on the autism spectrum,

Table 5 Results of the HMRAs of the problem- and benefit-score regressed on AQ-score

\begin{tabular}{|c|c|c|c|c|}
\hline & \multicolumn{2}{|l|}{ Problems } & \multicolumn{2}{|l|}{ Benefits } \\
\hline & $R^{2}$ & $p$ & $R^{2}$ & $p$ \\
\hline Constructive & $8.99 \%$ & .021 & $15.92 \%$ & $<.001$ \\
\hline Self-directive & $13.66 \%$ & .002 & $13.19 \%$ & .002 \\
\hline Collaborative & $34.43 \%$ & $<.001$ & $19.39 \%$ & $<.001$ \\
\hline Contextual & $21.52 \%$ & $<.001$ & $24.65 \%$ & $<.001$ \\
\hline Total & $30.74 \%$ & $<.001$ & $23.05 \%$ & $<.001$ \\
\hline
\end{tabular}

while this is not true according to more objective measures such as grades. Because most current research on students with ASD in higher education is qualitative (e.g. Gobbo and Shmulsky 2014; Knott and Taylor 2014), this incompatibility between reported problems and benefits and objective performance also poses a problem to several already published studies. It could, for instance, mean that students reporting having difficulties with group work in fact do not perform that bad in groups; it could be more of a feeling than an actual existing problem. This does, however, not mean that the reported experience of more problems and fewer benefits is not a matter of concern. As stated before, people with ASD generally experience more stress, depression, and anxiety than TD individuals (Ghaziuddin et al. 2002; Gillott and Standen 2007; Kim et al. 2000; Sterling et al. 2008). These feelings that are evoked by e.g. group work are certainly not imaginary; they are real and need to be addressed. After all, not only grades count but also the way those grades are achieved. All students, including students high on the autism spectrum, deserve a pleasant way of studying.

A last possible explanation for the discrepancy between reported and objectively quantified problems is that students with ASD accommodate well to problems they experience in PBL, and that they therefore perform good, despite still having the feeling of experiencing problems. One way to confirm this explanation would be if the negative relationship between grades and ASD symptomatology was stronger among firstyear students than students from higher years. Although our sample did not lend itself well to examine this, regression analyses split according to study year do support this accommodation hypothesis. The percentage variance in performance explained by AQ-score was higher among the 73 first-year students $(4.54 \%)$ than among the 34 second-, third-, and fourth-year students (2.45\%). This supports the accommodation hypothesis because it indicates that ASD symptomatology is a better predictor of grades among first-year students than it is among higher-year students, which might be attributable to a change in the students themselves. If students who score high on ASD symptomatology get used to working in PBL, it might be a change for the better. This idea of accommodation can be related to the concept of desirable difficulties. The practice students scoring high on ASD symptomatology obtain in PBL could explain the combination of normal grades with more reported problems and fewer reported benefits. A practice environment in which the student struggles a bit in learning might not be bad, but might in fact provide an ideal learning environment, which gives a feeling of experiencing more problems and fewer benefits, but which also gives good objective outcomes (grades). This could be beneficial within educational settings as well as in post-educational settings; if certain problems are already experienced in the protective and accommodating environment of the university, it might be easier to face them in real life, such as in a job. 
As said before, the current sample was not ideal for testing the accommodation hypothesis. A sample with more second-, third-, and four-year students would be needed to thoroughly examine this explanation of the lacking relationship between grades and ASD symptomatology. In addition, it would be useful to examine a more detailed timeline. The data might reveal more if grades are monitored per month or course instead of per year, because looking at the data in periods of years might not be precise enough to see the effects of the hypothesised accommodation mechanism. Lastly, the possibility exists that the high-AQ students in the current sample that do not accommodate well drop out. Therefore, a longitudinal design would provide useful additional information.

Besides examining the discussed possible accommodation effect in a longitudinal sample that is better suited for that purpose, there are other areas future studies should look into. First of all, the current exploratory results need to be replicated to see how strong the findings are. Another issue for future research concerns direct comparison of the PBL curriculum to a traditional curriculum to examine if the promises PBL makes are also valid for students scoring high on the autism spectrum. Research on TD students shows that PBL is related to higher long-term knowledge and skills, faster graduation, and lower dropout (Schmidt et al. 2009; Severiens and Schmidt 2009; Susarla et al. 2003). The question rises if this is also the case for high-AQ students. Schmidt et al. (2012) show that weaker students who drop out in regular curricula are retained in PBL programs. Although students scoring high on the autism spectrum should certainly not be characterised as weak, it is possible that they are a group of students that is also better retained in PBL compared to traditional curricula. This is related to the accommodation hypothesis; if students with high AQ-scores accommodate to the characteristics of PBL and succeed in working in PBL, can they likewise accommodate to characteristics of traditional university curricula, or do they fail and drop out? If the latter is true, PBL would still be a superior choice for students scoring high on the autism spectrum, although they do experience more problems and fewer benefits of PBL than students with less autistic traits. It could be the best choice of two bad options.

However, studying at university should not be a bad option. Students with ASD possess talents that are wasted if not used, and deserve to study in a pleasant way. Therefore, an important part of future research should focus on educational interventions, e.g. based on PBL characteristics. One example concerns having meetings at structured times. As explained before, PBL offers mandatory meetings at structured days and times during the week. Every course (every 5 weeks), students are sorted into an early (in the morning) or a late (in the afternoon) tutorial meeting group. For students with e.g. ASD, the possibility exists to structure their schedule by filing an early/late preference, so that all their meetings are at the exact same time: either in the morning or in the afternoon, depending on their choice. This policy creates more predictability, and helps in structuring time. It is an example of a simple intervention that strengthens an advantage of PBL.

Looking back at the current findings, it is important to acknowledge that the present study did not examine students with an ASD diagnosis. However, the current nonpathological sample provided much information concerning the relationship between ASD symptomatology and study experiences and performance in PBL. Though the findings show that students who score high on ASD symptomatology do perform equal to students who score low, the former group does report experiencing more problems and fewer benefits from studying in PBL. This means that although PBL seems like a good fit for students with ASD, there is also room for improvement. The high problems in the collaborative PBL element suggest that arrangements focusing on less group work, smaller groups, and more instruction in how to function well in groups could bring about improvement in experienced problems. The lack of benefits concerning the contextual component of PBL indicates that much can be won by creating PBL study problems that change more gradually in context, especially since transfer is such a critical element of education. Therefore, the current findings provide clear pointers for accommodating to the needs of students with ASD, both in PBL and traditional curricula. This will be a necessary step in making higher education more accessible to students scoring high on the autism spectrum.

Acknowledgements We thank the anonymous reviewers for their helpful comments on earlier drafts of this manuscript.

Author Contributions KdG conceived the study, participated in its design, performed the measurements and statistical analyses, and interpreted the data. GS participated in the design and coordination of the study, and revised the manuscript critically for important intellectual content. All authors read and approved the final manuscript.

\section{References}

American Psychiatric Association. (2013). Diagnostic and statistical manual of mental disorders (5th ed.). Washington, DC: Author.

Asperger, H. (1944). Die "autistischen Psychopathen" im Kindesalter. Archiv fur Psychiatrie und Nervenkrakheiten, 117, 76-136.

Asperger, H. (1991). 'Autistic psychopathy' in childhood (U. Frith, Trans.) In U. Frith (Ed.), Autism and Asperger syndrome (pp. 3792). New York, NY: Cambridge University Press.

Austin, E. J. (2005). Personality correlates of the broader autism phenotype as assessed by the Autism Spectrum Quotient (AQ). Personality and Individual Differences, 38, 451-460.

Baron-Cohen, S., Wheelwright, S., Skinner, R., Martin, J., \& Clubley, E. (2001). The Autism-Spectrum Quotient (AQ): evidence from Asperger Syndrome/high-functioning autism, males and females, scientists and mathematicians. Journal of Autism and Developmental Disorders, 31, 5-17.

Baxter, A., Brugha, T., Erskine, H., Scheurer, R., Vos, T., \& Scott, J. (2015). The epidemiology and global burden of autism spectrum disorders. Psychological Medicine, 45, 601-613. 
Beardon, L., Martin, N., \& Woolsey, I. (2009). What do students with Asperger syndrome or high-functioning autism want at college and university? (In their own words). Good Autism Practice, 10, 35-43.

Capon, N., \& Kuhn, D. (2004). What's so good about Problem-Based Learning? Cognition and Instruction, 22, 61-79.

De Grave, W. S., Schmidt, H. G., \& Boshuizen, H. P. A. (2001). Effects of problem-based discussion on studying a subsequent text: a randomized trial among first year medical students. Instructional Science, $29,33-44$.

Dolmans, D. H. J. M., De Grave, W., Wolfhagen, I. H. A. P., \& Van Der Vleuten, C. P. M. (2005). Problem-based learning: future challenges for educational practice and research. Medical Education, 39, 732741.

Dunn, C., Chambers, D., \& Rabren, K. (2004). Variables affecting students' decisions to drop out of school. Remedial and Special Education, 25, 314-323.

Frith, U., \& Happé, F. (1994). Autism: beyond "theory of mind". Cognition, 50, 115-132.

Gelbar, N. W., Smith, I., \& Reichow, B. (2014). Systematic review of articles describing experience and supports of individuals with autism enrolled in college and university programs. Journal of Autism and Developmental Disorders, 44, 2593-2601.

Ghaziuddin, M., Ghaziuddin, N., \& Greden, J. (2002). Depression in persons with autism: implications for research and clinical care. Journal of Autism and Developmental Disorders, 32, 299-306.

Gillott, A., \& Standen, P. J. (2007). Levels of anxiety and sources of stress in adults with autism. Journal of Intellectual Disabilities, 11, 359370 .

Gobbo, K., \& Shmulsky, S. (2014). Faculty experience with college students with Autism Spectrum Disorders: a qualitative study of challenges and solutions. Focus on Autism and Other Developmental Disabilities, 29, 13-22.

Grandin, T., \& Johnson, C. (2005). Animals in translation. San Diego, CA: Harcourt.

Hoekstra, R. A., Bartels, M., Cath, D. C., \& Boomsma, D. I. (2008). Factor structure, reliability and criterion validity of the AutismSpectrum Quotient (AQ): a study in Dutch population and patient groups. Journal of Autism and Developmental Disorders, 38, 15551566.

Kanner, L. (1943). Autistic disturbances of affective contact. Nervous Child, 2, 217-250.

Kim, J. A., Szatmari, P., Bryson, S. E., Streiner, D. L., \& Wilson, F. J. (2000). The prevalence of anxiety and mood problems among children with autism and Asperger syndrome. Autism, 4, 117-132.

Kirschner, P. A., Sweller, J., \& Clark, R. E. (2006). Why minimal guidance during instruction does not work: An analysis of the failure of constructivist, discovery, problem-based, experiential, and inquirybased teaching. Educational Psychologist, 41, 75-86.

Knott, F., \& Taylor, A. (2014). Life at university with Asperger syndrome: a comparison of student and staff perspectives. International Journal of Inclusive Education, 18, 411-426.

Loyens, S. M. M., Kirschner, P. A., \& Paas, F. (2012). Problem-based learning. In K. R. Harris, S. Graham, \& T. Urdan (Eds.), APA Educational psychology handbook: vol. 3. Application to learning and teaching (pp. 403-425). Washington, DC: American Psychological Association.

Mirenda, P. L., \& Donnellan, A. M. (1987). Issues in curriculum development. In D. J. Cohen, A. M. Donnellan, \& R. Paul (Eds.), Handbook of autism and pervasive developmental disorders. New York, NY: John Wiley and Sons.

Mulder, A. M., \& Cashin, A. (2014). The need to support students with autism at university. Issues in Mental Health Nursing, 35, 664-671.

Murray, A. L., Booth, T., McKenzie, K., \& Kuenssberg, R. (2016). What range of trait levels can the Autism-Spectrum Quotient (AQ) measure reliably? An item response theory analysis. Psychological Assessment, 28, 673-683.
Norman, G. R., \& Schmidt, H. G. (1992). The psychological basis of Problem-Based Learning: a review of the evidence. Academic Medicine, 67, 557-565.

Pinder-Amaker, S. (2014). Identifying the unmet needs of college students on the autism spectrum. Harvard Review of Psychiatry, 22, $125-137$.

Plaisted, K. C. (2001). Reduced generalization in autism: an alternative to weak central coherence. In J. A. Burack, T. Charman, N. Yirmiya, \& P. R. Zelazo (Eds.), The development of autism: perspectives from theory and research. Mahwah, NJ: Lawrence Erlbaum Associates.

Podsakoff, P. M., \& Organ, D. W. (1986). Self-reports in organizational research: problems and prospects. Journal of Management, 12, 531544.

Podsakoff, P. M., MacKenzie, S. B., Lee, J., \& Podsakoff, N. P. (2003). Common method biases in behavioral research: a critical review of the literature and recommended remedies. Journal of Applied Psychology, 88, 879-903.

Podsakoff, P. M., MacKenzie, S. B., \& Podsakoff, N. P. (2012). Sources of method bias in social science research and recommendations on how to control it. Annual Review of Psychology, 63, 539-569.

Schmidt, H. G., Loyens, S. M. M., Van Gog, T., \& Paas, F. (2007). Problem-based learning is compatible with human cognitive architecture: commentary on Kirschner, Sweller, and Clark (2006). Educational Psychologist, 42, 91-97.

Schmidt, H. G., Cohen-Schotanus, J., \& Arends, L. R. (2009). Impact of problem-based, active learning on graduation rates for 10 generations of Dutch medical students. Medical Education, 43, 211-218.

Schmidt, H. G., Muijtjens, A. M. M., Van der Vleuten, C. P. M., \& Norman, G. R. (2012). Differential student attrition and differential exposure mask effects of Problem-Based Learning in curriculum comparison studies. Academic Medicine, 87, 463-475.

Severiens, S. E., \& Schmidt, H. G. (2009). Academic and social integration and study progress in Problem Based Learning. Higher Education, 58, 59-69.

Slavin, R. E. (2005). Educational psychology: theory and practice. Boston: Allyn and Bacon.

Spek, A. A. (2010). Mindfulness bij volwassenen met autisme. Amsterdam: Hogrefe Uitgevers.

Spek, A. A., Scholte, E. M., \& Van Berckelaer-Onnes, I. A. (2010). Theory of mind in adults with HFA and Asperger syndrome. Journal of Autism and Developmental Disorders, 40, 280-289.

Spek, A. A., Scholte, E. M., \& Van Berckelaer-Onnes, I. A. (2011). Local information processing in adults with High Functioning Autism and Asperger syndrome: the usefulness of neuropsychological tests and self-reports. Journal of Autism and Developmental Disorders, 4, 859-869.

Sterling, L., Dawson, G., Estes, A., \& Greenson, J. (2008). Characteristics associated with presence of depressive symptoms in adults with Autism Spectrum Disorder. Journal of Autism and Developmental Disorders, 38, 1011-1018.

Stevenson, J. L., \& Hart, K. R. (2017). Psychometric properties of the Autism-Spectrum Quotient for assessing low and high levels of autistic traits in college students. Journal of Autism and Developmental Disorders, 47, 1838-1853.

Strobel, J., \& Van Barneveld, A. (2009). When is PBL more effective? A meta-synthesis of meta-analyses comparing PBL to conventional classrooms. Interdisciplinary Journal of Problem-Based Learning, $3,44-58$

Susarla, S. M., Medina-Martinez, N., Howell, T. H., \& Karimbux, N. Y. (2003). Problem-based learning: effects on standard outcomes. Journal of Dental Education, 67, 1003-1010.

Van Blankenstein, F. M., Dolmans, D. H. J. M., Van Der Vleuten, C. P. M., \& Schmidt, H. G. (2011). Which cognitive processes support learning during small-group discussion? The role of providing explanations and listening to others. Instructional Science, 39, 189204. 
Wei, X., Christiano, E. R. A., Yu, J. W., Shattuck, P., \& Newman, L. A. (2014). Postsecondary pathways and persistence for STEM versus non-STEM majors: among college students with an Autism Spectrum Disorder. Journal of Autism and Developmental Disorders, 44, 1159-1167.

Wicks-Nelson, R., \& Israel, A. C. (2012). Abnormal child and adolescent psychology. Upper Saddle River: Pearson.
Williams, L. J., \& Brown, B. K. (1994). Method variance in organizational behavior and human resources research: effects on correlations, path coefficients, and hypothesis testing. Organizational Behavior and Human Decision Processes, 57, 185-209.

Wing, L. (1988). The autistic continuum. In L. Wing (Ed.), Aspects of autism: biological research. London: Gaskell/Royal College of Psychiatrists. 